\title{
ISCHEMIC STROKE REGISTRY IN EGYPT: HOSPITAL BASED STUDY
}

\section{By \\ Tarek Ibrahim Meneci, Ahmed Hassan El-Sheshiny and Mohamed Saber Mohamed}

Department of Neurology, Faculty of Medicine, Al-Azhar University, Egypt

E-mail: afathyneuro@gmail.com

\begin{abstract}
Background: Stroke is defined by the World Health Organization(WHO) as 'a clinical syndrome consisting of rapidly developing clinical signs of focal (or sometimes global) disturbance of cerebral function lasting more than 24 hours or leading to death with no apparent cause other than a vascular origin.

Objective: To study the pattern of ischemic stroke subtypes in a sample Egyptian patients, common risk factor profiles and management methods.

Patients: A retrospective study was conducted on 321 patients who were admitted to Al-Azhar University Hospitals and Nasser Institute with a main primary diagnosis of acute ischemic stroke during the period from January 2017 until December 2018.

Results: Small vessel strokes were the most common accounting for $51.1 \%$ of all patients, followed by large vessel getting affected $24 \%$ of the cases. Cardio embolic stroke was present in $20.8 \%$ of the cases, Hypertension was the most prevalent risk factor among patients accounting for $61.1 \%$, diabetes $(49.5 \%)$, obesity (38.6\%), and smoking (32.1\%). A significant difference in stroke severity among stroke patients regarding smoking status was found in univariate analysis and obesity. Multivariate analysis using multiple linear regressions showed that the relationship with obesity was significant.

Conclusion: In spite of the high prevalence of stroke risk factors among the study patients, the power wasn't enough to show any association with stroke severity except for smoking and obesity, where smokers and obese patients are more likely to have higher stroke severity.
\end{abstract}

Keywords: Stroke, retrospective, ischemic, Egyptian, vascular.

\section{INTRODUCTION}

Stroke is defined by the World Health Organization as 'a clinical syndrome consisting of rapidly developing clinical signs of focal (or sometimes global) disturbance of cerebral function lasting more than 24 hours or leading to death with no apparent cause other than a vascular origin (Coupland and Thapar, 2017).

There were an estimated 42 million prevalent cases of cerebrovascular disease worldwide, including an estimated 5.39 million acute first ischemic strokes, and 3.58 million acute first hemorrhagic and other strokes (Feigin et al., 2015). Stroke considered as the second most common cause of deaths (Roth et al., 2017).

The World Health Organization (WHO) estimates that $85 \%$ of stroke deaths now occur in low and middleincome countries and that disabilityadjusted life years lost to stroke are almost seven times that in high-income countries. 
Egypt is the most populated nation in the Middle East and the third most populous on the African continent. Stroke is a major health problem among the Egyptian population, furthermore, although Egypt is the most populous nation in the middle east, there is no active national wide registry for stroke and accurate data on stroke epidemiology are scarce, However, Researches on this topic is essential for planning appropriate management programs, effectively applying primary prevention strategies and improving health resources in Egypt (Abd-Allah et al., 2014).

A number of community base studies, particularly investigation conducted in governorates in Upper Egypt between 1992 and 2013 have reported the incidences and prevalence of stroke in Egypt. Arterial hypertension, diabetes mellitus, cigarette smoking, hyperlipidemia, and advancing age have been identified as risk factors for stroke (Khedr et al., 2014).

The present work aimed to study the pattern of ischemic stroke in Egyptian patients as regard the relative prevalence of ischemic stroke subtypes, the demographic data, common risk factor profiles and management methods, comparing these data with national and international data for more clarification of the situation in Egypt.

\section{PATIENTS AND METHODS}

This was a retrospective study on patients who were admitted to Stroke unit and/or intensive care unit of Al-Azhar University Hospitals and Nasser Institute with a main discharge diagnosis of acute ischemic stroke during the period from January 2017 until December 2018.

\section{Exclusion criteria:}

Transient Ischemic Attack (TIA), intracerebral hemorrhage, subarachnoidal hemorrhage and cerebral sinus venous thrombosis.

The data encoded in this study was registered in safe implementation of treatment in stroke (SITS international) and was divided into the following categories:

\section{Demographic data and Risk factors:}

1. Hypertension (on antihypertensive medications or established history of $\mathrm{Bp}>160 / 90 \mathrm{~mm} \mathrm{hg}$ on at least two occasions).

2. Diabetes Mellitus (past history of Diabetes Mellitus, at two independent readings before the stroke or elevated glycated hemoglobin on admission or on anti-diabetic medications).

3. Hyperlipidemia (previous history of hyperlipidemia, on cholesterol lowering drugs or persistent elevation of plasma level of cholesterol, triglycerides, LDL and HDL BMI >30 $\mathrm{kg} / \mathrm{m}^{2}$.

4. Smoking Classified into two categories: Nonsmokers/former smoker (never smoked regularly or quit regular smoking >5 years) and Smokers (regular daily cigarettes smoking > 5 years).

5. History of TIA, Migraine and family history of strokes.

6. Laboratory.

7. ECG. 
8. Carotid duplex.

9. Trans thoracic or trans esophageal Echo if needed.

10. Neuro imaging data.

11. Clinical outcome and complications.

\section{Statistical analysis:}

Statistical analysis of the study results are presented as the mean, median standard deviation, frequency; chi-square and linear regression model were used to test significance for qualitative data. $\mathrm{P}<0.05$ was considered significant.

\section{RESULTS}

This stroke registry gathered data from 321 stroke patients in Al-Azhar university hospitals and Nasser institute hospital. Mean age of stroke patients was 59 years and $(76.6 \%)$ of cases were more than 50 years old, there were $53.3 \%$ male and $46.7 \%$ females, $61.1 \%$ of cases were hypertensive, $49.5 \%$ were diabetic, $41.1 \%$ of cases had hyperlipidemia, $38.6 \%$ were obese while $32.1 \%$ were Smokers. $54.5 \%$ of cases had no intervention, $40.8 \%$ were taken rTPA and only $4.7 \%$ had Thrombectomy Intervention. More than half of cases $(78.5 \%)$ had no history of TIA. The range of systolic blood pressure at admission was $80.0-210.0$ and its mean was 146, the range of diastolic blood pressure at admission was 40.0 140.0 and its mean was 90 , the range of RBS at admission was $85.0-450.0$ and its mean was 184 and the range of total leucocytes count (TLC) 3.3_46 and its mean 8.758. $49.8 \%$ of cases were arrived in the golden hours (4.5 hours or less), $31.8 \%$ of cases came after 4.5 hours but within the first 24 hours and only $18.4 \%$ of cases came after 24 hours. $83.4 \%$ of cases initially admitted to stroke unit (Table 1). 
OSAMA EL-GHANNAM et al.,

Table (1): Distribution of the studied cases according to demographic data and baseline clinical factors $(n=321)$

\begin{tabular}{|c|c|c|c|}
\hline \multicolumn{2}{|l|}{ Variables } & $\begin{array}{c}\text { Number of } \\
\text { patients }\end{array}$ & Percentage \\
\hline \multirow{2}{*}{ Sex } & Male & 171 & 53.3 \\
\hline & Female & 150 & 46.7 \\
\hline \multirow{2}{*}{ Age } & $\leq 50$ & 75 & 23.4 \\
\hline & $>50$ & 246 & 76.6 \\
\hline \multirow{2}{*}{ Hypertensive } & No & 125 & 38.9 \\
\hline & Yes & 196 & 61.1 \\
\hline \multirow{2}{*}{ Diabetic } & No & 162 & 50.5 \\
\hline & Yes & 159 & 49.5 \\
\hline \multirow{2}{*}{ Obese } & No & 197 & 61.4 \\
\hline & Yes & 124 & 38.6 \\
\hline \multirow{3}{*}{ Smoking } & Non-smoker & 178 & 55.4 \\
\hline & Smoker & 103 & 32.1 \\
\hline & X-smoker & 40 & 12.5 \\
\hline \multirow{2}{*}{ TIA history } & No & 252 & 78.5 \\
\hline & Yes & 69 & 21.5 \\
\hline \multirow{2}{*}{ Hyperlipidemia } & No & 189 & 58.9 \\
\hline & Yes & 132 & 41.1 \\
\hline \multirow{3}{*}{ Onset } & $\leq 4.5$ & 160 & 49.8 \\
\hline & 4.5 to $<24 \mathrm{hr}$. & 102 & 31.8 \\
\hline & $24 \geq$ & 59 & 18.4 \\
\hline \multirow{3}{*}{ Intervention } & No & 175 & 54.5 \\
\hline & Thrombectomy & 15 & 4.7 \\
\hline & rTPA & 131 & 40.8 \\
\hline $\begin{array}{c}\text { Type of } \\
\text { admission }\end{array}$ & $\begin{array}{l}\text { Stroke Unit } \\
\text { Ward }\end{array}$ & $\begin{array}{c}269 \\
52\end{array}$ & $\begin{array}{l}83.8 \\
14.2\end{array}$ \\
\hline complications & $\begin{array}{c}\text { Hemorrhagic transformation } \\
\text { Pneumonia } \\
\text { UTI } \\
\text { Pulmonary embolism } \\
\text { DVT }\end{array}$ & $\begin{array}{c}14 \\
22 \\
8 \\
0 \\
2\end{array}$ & $\begin{array}{c}4.4 \\
6.9 \\
2.5 \\
0 \\
.6\end{array}$ \\
\hline \multicolumn{2}{|r|}{ Variable } & Mean \pm SD & Range \\
\hline \multicolumn{2}{|r|}{ Age } & $58.66 \pm 13.36$ & $17.0-89.0$ \\
\hline \multicolumn{2}{|c|}{ Blood pressure } & $146.3 \pm 27.05$ & $130.0-160.0$ \\
\hline \multicolumn{2}{|r|}{ Pulse rate } & $89.60 \pm 13.59$ & $80.0-100.0$ \\
\hline \multirow{2}{*}{\multicolumn{2}{|c|}{$\begin{array}{l}\text { Random blood sugar } \\
\text { Total leucocytes count }\end{array}$}} & $183.6 \pm 89.08$ & $115.0-235.0$ \\
\hline & & $8.758 \pm 5.403$ & $3.3 \_46$ \\
\hline
\end{tabular}

Small vessels strokes were the most common accounting for $51.1 \%$ of all patients followed by large vessels getting affected in $24 \%$, cardio embolic stroke was present in $20.8 \%$ of the cases. $82.3 \%$ of cases had anterior circulation distribution, and $17.1 \%$ had posterior circulation distribution (Table 2). 
ISCHEMIC STROKE REGISTRY IN EGYPT: HOSPITAL BASED...

Table (2): Distribution of the stroke-sub types among the study patients

\begin{tabular}{|c|c|c|c|}
\hline \multicolumn{1}{|c|}{ Patients } & Number of patients & Percentage \\
\hline \multirow{4}{*}{ Stroke type } & Small & 164 & 51.1 \\
\cline { 2 - 4 } & Large & 77 & 24.0 \\
& Embolic & 67 & 20.9 \\
& Un-determined & 13 & 4 \\
\hline \multirow{3}{*}{ Site } & Anterior & 264 & 82.3 \\
\cline { 2 - 4 } & Posterior & 55 & 17.1 \\
\cline { 2 - 4 } & Both & 2 & 0.6 \\
\hline
\end{tabular}

Most common infarcts location was in parietal 29\%, basal ganglia $24.3 \%$ and cerebellar in $8.4 \%$ (Table 3).

Table (3): Infarct Location $(n=321)$

\begin{tabular}{|l|c|}
\hline Location of infarct & n (\%) \\
\hline Frontal & $16(5 \%)$ \\
\hline Parietal & $93(29 \%)$ \\
\hline Temporal & $27(8.4 \%)$ \\
\hline Occipital & $5(1.6 \%)$ \\
\hline Basal ganglia & $78(24.3 \%)$ \\
\hline Internal capsule & $19(5.9 \%)$ \\
\hline Thalamus & $14(4.4 \%)$ \\
\hline Cerebellar & $27(8.4 \%)$ \\
\hline Mid brain & $4(1.2 \%)$ \\
\hline Pontine & $8(2.5 \%)$ \\
\hline Medullary & $11(3.4 \%)$ \\
\hline More than one site & $19(5.9 \%)$ \\
\hline
\end{tabular}

ECG was done for all patients, cardiac co-morbidity was present in $39.9 \%$ of cases on ECG, Atrial fibrillation was the most common cardiac abnormality $(20.9 \%$ of all cases), and ischemic changes in $18.1 \%$.
The hospital stays for the studied cases range from 1 day to 45 days with a mean stay of $7.31 \pm 6.35$.

$48.0 \%$ of cases was Moderate $(6-11)$ NIHs, 27.4\% Mild (0 - 5), 24.6\% Severe (12 or more) NIHs, and Mean \pm SD. of NIHs is $8.37 \pm 4.08$ as (Figure 1).

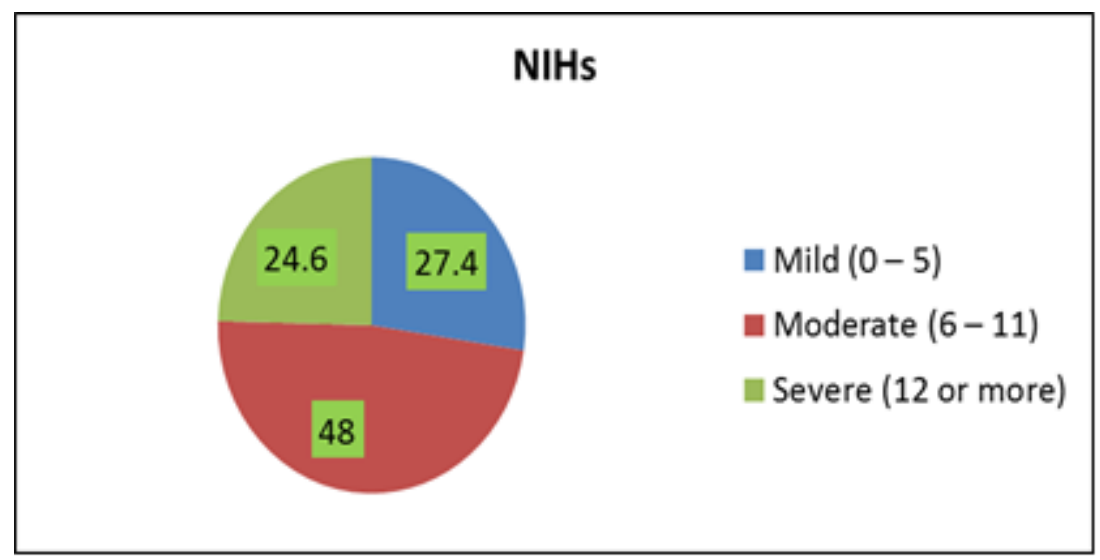

Figure (1): Bar charts showing Comprise the studied cases as regard NIHSs 
Most of cases (94.7\%) had no Fits on onset (Table 4).

Table (4): Distribution of the studied cases according to present of fits on onset

\begin{tabular}{|l|c|c|c|}
\hline \multirow{2}{*}{ Variables } & Patients & Number of patients & Percentage \\
\hline \multirow{2}{*}{ Fits on onset } & YES & 304 & 94.7 \\
\cline { 2 - 4 } & NO & 17 & 5.3 \\
\hline
\end{tabular}

Comparison between TLC regarding to age, gender, stroke subtype, circulation and stroke severity, this table shows there was a statistical significant difference between TLC as a marker of infection as regard Age and gender where old age and female cases were more liable to infection (Table 5).

Table (5): Relation between Total Leucocytic Count and other factors $(n=321)$

\begin{tabular}{|l|c|c|c|c|}
\hline Factors & Normal TLC $(>11)$ & High TLC $(\leq 11)$ & $\mathrm{x}^{2}$ & $\mathrm{P}$ \\
\hline Age & 197 & 49 & 25.3549 & 0.00001 \\
$>50$ & 38 & 37 & & \\
$\leq 50$ & 131 & 40 & 10.2765 & 0.001347 \\
\hline Gender & 90 & 60 & & \\
Males & 58 & 19 & & \\
Females & 146 & 59 & 3.1978 & 0.36212 \\
\hline Stroke subtype & 20 & 6 & & \\
Large & 12 & 1 & & \\
Small & 190 & 76 & 1.0446 & 0.306762 \\
Embolic & 43 & 12 & & \\
Undetermined & 63 & 23 & & \\
\hline Circulation & 110 & 44 & 0.5447 & 0.761587 \\
Anterior & 60 & 19 & & \\
posterior & & & \\
\hline Severity & & & \\
Mild & Moderate & & & \\
Sever & & & & \\
\hline
\end{tabular}

Tests of significance were conducted using Chi-Square with Monte-Carlo method

There was no statistical significant difference between the grades of NIHSs as regard Age and that there was a statistical significant difference between NIHSs as regard Smoking and obesity, there was no statistical significant difference between NIHSs as regard hypertension and Diabetes (Table 6). 
Table (6): Relation between NIHs and age $(n=321)$

\begin{tabular}{|c|c|c|c|c|c|c|c|c|}
\hline Variables & $\begin{array}{r}\text { Milc } \\
\text { (n }\end{array}$ & $\begin{array}{l}-5) \\
38)\end{array}$ & & & Sev & $\begin{array}{l}(>12) \\
79)\end{array}$ & $x^{2}$ & $\mathrm{P}$ \\
\hline & No. & $\%$ & No. & $\%$ & No. & $\%$ & & \\
\hline$\leq 50$ & 20 & 22.7 & 35 & 22.7 & 20 & 25.3 & & \\
\hline$>50$ & 68 & 77.3 & 119 & 77.3 & 59 & 74.7 & 0.223 & 0.894 \\
\hline $\begin{array}{l}\text { Diabetic } \\
\text { No } \\
\text { Yes }\end{array}$ & $\begin{array}{l}44 \\
44\end{array}$ & $\begin{array}{l}50.0 \\
50.0\end{array}$ & $\begin{array}{l}81 \\
73\end{array}$ & $\begin{array}{l}52.6 \\
47.4\end{array}$ & $\begin{array}{l}37 \\
42\end{array}$ & $\begin{array}{l}46.8 \\
53.2\end{array}$ & $\begin{array}{c}0.704 \\
1\end{array}$ & 0.70321 \\
\hline $\begin{array}{l}\text { HTN } \\
\text { No } \\
\text { Yes }\end{array}$ & $\begin{array}{l}38 \\
50\end{array}$ & $\begin{array}{l}43.2 \\
56.8\end{array}$ & $\begin{array}{l}63 \\
91 \\
\end{array}$ & $\begin{array}{l}40.9 \\
59.1\end{array}$ & $\begin{array}{l}24 \\
55 \\
\end{array}$ & $\begin{array}{l}30.4 \\
69.6 \\
\end{array}$ & $\begin{array}{c}3.351 \\
8\end{array}$ & 0.18714 \\
\hline $\begin{array}{l}\text { Smoker } \\
\text { Non smoker } \\
\text { Smoker } \\
\text { X-smoker }\end{array}$ & $\begin{array}{l}55 \\
17 \\
16\end{array}$ & $\begin{array}{l}62.5 \\
19.3 \\
18.2\end{array}$ & $\begin{array}{l}84 \\
57 \\
13\end{array}$ & $\begin{array}{c}54.5 \\
37.0 \\
8.4\end{array}$ & $\begin{array}{l}39 \\
29 \\
11\end{array}$ & $\begin{array}{c}49.40 \\
36.7 \\
13.4\end{array}$ & $\begin{array}{c}11.94 \\
4\end{array}$ & 0.01777 \\
\hline $\begin{array}{l}\text { Obesity } \\
\text { NO } \\
\text { YES }\end{array}$ & $\begin{array}{l}66 \\
22 \\
\end{array}$ & $\begin{array}{l}75 \\
25 \\
\end{array}$ & $\begin{array}{l}91 \\
63\end{array}$ & $\begin{array}{l}59.1 \\
40.9\end{array}$ & $\begin{array}{l}40 \\
39\end{array}$ & $\begin{array}{l}50.6 \\
49.4\end{array}$ & $\begin{array}{c}10.59 \\
6\end{array}$ & 0.05001 \\
\hline
\end{tabular}

*: P value $<0.05$. Tests of significance were conducted using Chi-Square with Monte-Carlo method

The linear regression model showed that males, hypertensive patients or smokers were higher in NIHSs score, although the effects of each of age, gender, DM, HTN, smoking, and TIA history on NIHS score after adjusting for other variables were not significant. However, obesity had an independent significant effect on NIHS score adjusted for other variables where obese patients were more likely to have 1.83 more NIHS score than non-obese patients (Table 7).

Table (7): The relationship between NIHS score (dependent variable) and each of gender, age, DM, HTN, smoking, obesity, and history of TIA using linear regression model

\begin{tabular}{|c|c|c|c|c|c|}
\hline Independent variables & Beta & $\begin{array}{c}\text { Std. } \\
\text { Error }\end{array}$ & T & $\begin{array}{c}\text { P- } \\
\text { value }\end{array}$ & VIF \\
\hline (Constant) & $\mathbf{8 . 5 8 7}$ & $\mathbf{1 . 1 9 2}$ & $\mathbf{7 . 2 0 5}$ & $\mathbf{0 . 0 0 0}$ & \\
\hline Female & $\mathbf{- 0 . 3 6 9}$ & $\mathbf{0 . 7 3 2}$ & $\mathbf{- 0 . 5 0 5}$ & $\mathbf{0 . 6 1 4}$ & $\mathbf{2 . 6 5 0}$ \\
\hline Age & $\mathbf{- 0 . 0 1 3}$ & $\mathbf{0 . 0 1 8}$ & $\mathbf{- 0 . 7 0 9}$ & $\mathbf{0 . 4 7 9}$ & $\mathbf{1 . 2 2 5}$ \\
\hline Diabetic & $\mathbf{- 0 . 4 4 0}$ & $\mathbf{0 . 5 4 1}$ & $-\mathbf{0 . 8 1 5}$ & $\mathbf{0 . 4 1 6}$ & $\mathbf{1 . 4 5 1}$ \\
\hline HTN & $\mathbf{0 . 1 9 9}$ & $\mathbf{0 . 5 6 6}$ & $\mathbf{0 . 3 5 1}$ & $\mathbf{0 . 7 2 6}$ & $\mathbf{1 . 5 1 6}$ \\
\hline Smoker or ex-smoker & $\mathbf{0 . 5 6 4}$ & $\mathbf{0 . 7 4 4}$ & $\mathbf{0 . 7 5 8}$ & $\mathbf{0 . 4 4 9}$ & $\mathbf{2 . 7 0 3}$ \\
\hline Obese $\left(\right.$ BMI $\left.>30 k g / \mathbf{m}^{2}\right)$ & $\mathbf{1 . 8 2 8}$ & $\mathbf{0 . 5 7 0}$ & $\mathbf{3 . 2 0 6}$ & $\mathbf{0 . 0 0 1} *$ & $\mathbf{1 . 5 3 0}$ \\
\hline TIA & $\mathbf{- 0 . 5 0 9}$ & $\mathbf{0 . 5 5 9}$ & $\mathbf{- . 9 1 1}$ & $\mathbf{0 . 3 6 3}$ & $\mathbf{1 . 0 5 3}$ \\
\hline
\end{tabular}

$\mathrm{VIF}=$ variance inflation factor 


\section{OSAMA EL-GHANNAM et al.,}

\section{DISCUSSION}

Epidemiological studies have identified several risk factors for ischemic stroke, including hypertension, smoking, diabetes mellitus and hemostatic factors. However, few prospective studies have characterized risk factors for specific subtypes of ischemic stroke. 2-4 Because the pathogenesis, prognosis, and treatment differ among subtypes, evaluating risk factors for individual subtypes may contribute to more effective primary and secondary prevention of ischemic stroke (Habibi-koolaee and Shahmoradi, 2018).

Regarding socio demographic data of the studied patients, their age is ranged from 17.0 - 89.0 years with mean of 58.66 \pm 13.36 years and $(76.6 \%)$ more than 50 years, there were $53.3 \%$ male and $46.7 \%$ females. Mean \pm SD. of age among male was $59.49 \pm 12.72$ years old, and was $57.73 \pm 14.04$ years old among female, $54.7 \%$ of male and $52.8 \%$ of female were $\leq 50$ years old.

Our study reported that small vessels strokes were the most common accounting for $51.1 \%$ of all patients followed by large vessels getting affected in $24 \%$, cardio embolic stroke was present in $20.8 \%$ of the cases which in agreement with Asian studies like Bum and Jong (2014) who record high proportion of small artery subtypes in Asian population.

The lower incidence of cardio embolic stroke in our hospital based study which was $(20.8 \%)$, so it is in contrast to the rates generally noted in stroke registries, which are often above $30 \%$ also stroke of undetermined a etiology was (4.1\%) of patients which also often around 30\% in most studies (Arboix and Alio, 2010).
Our results are supported by study of Khedr et al. (2014), as they reported that concerning the demographic and clinical data of studied prevalent cases of stroke, the mean age of our patients was 59.6611 years (range 28-91). This study conducted on 46 males and 28 females.

Furthermore, Soliman et al. (2018) demonstrated that one hundred sixtyseven patients with acute ischemic stroke were included in this cross-sectional descriptive study. Their age ranged from 15 to 90 years, with mean and standard deviation of $59.3 \pm 13.45$ years. In 90 males $(53.9 \%), 11$ patients of them were $\leq$ 45 years old, and in 77 females $(46.1 \%)$, 13 patients of them were $\leq 45$ years old.

The current study shows that $49.5 \%$ of cases were diabetic and $61.1 \%$ was hypertensive. There was high statistically significant difference between NIHs as regard smoking obesity, while there was no statistically significant difference between NIHs as regard Age, HTN and Diabetes.

Our results are supported by study of Soliman et al. (2018) reported that in their study, diabetes mellitus was recorded in $34.7 \%$ of patients which is slightly lower than El Tallawy et al. (2015) study done in Upper Egypt where diabetes mellitus was recorded in $36.5 \%$ of patients, whereas in Essa et al. (2011) study in Alexandria, diabetes mellitus was recorded in $66.8 \%$ of patients.

Similarly, Al Baghli et al. (2010) reported that the significant risk factors for stroke among Saudi population are hypertension followed by diabetes mellitus, heart disease, and smoking. It has been estimated that hypertension causes $54 \%$ of stroke in low-income and 
middle-income countries, followed by hypercholesterolemia (15\%) and tobacco smoking (12\%). More recent studies again found elevated blood pressure is by far the most important risk factor for stroke.

The present study shows that $55.5 \%$ of cases were nonsmoker, while $32.1 \%$ was Smoker. More than half of cases $(61.4 \%)$ were not obese. $77.6 \%$ of cases had abnormal cholesterol, with Mean \pm SD. is $184.1 \pm 56.85,72.3 \%$ of cases had abnormal TGA with Mean \pm SD. $155.7 \pm$ 85.80 , and only $12.1 \%$ had abnormal LDL with Mean \pm SD. $92.18 \pm 45.80$. There was no statistically significant difference between the Vessels as regard Cholesterol, TGA and there was high statistically significant difference between the Vessels as regard LDL.

Our results are supported by study of El Tallawy et al., (2015), as they reported that Smoking, diabetes, and hyperlipidemia were recorded in higher rates among ischemic strokes, and this is similar to results from a previous study done by Shah and Cole (2011) found that smoking was associated with $50 \%$ of hemorrhagic and $55 \%$ of ischemic stroke cases. He also found that cigarette smokers have an overall $51 \%$ increased risk of having a stroke. Patients with diabetes are two to three times more likely to have ischemic stroke when compared with non-diabetic individuals. Diabetes mellitus was associated with $26.25 \%$ of ischemic stroke.

Furthermore, Khedr et al. (2014) found that $67.57 \%$ had 1 or more risk factors of stroke, $37.84 \%$ had 2 risks factors and $20.27 \%$ had 3 risk factors. Hypertension being the most common risk factor (62.16\%), followed by diabetes mellitus
$(36.49 \%)$. Ischemic heart disease was recorded in $9.46 \%$ and a history of transient ischemic attack in $6.76 \%$, whereas rheumatic heart in $5.4 \%$, and systemic lupus erythromatosis in $1.35 \%$. $10.8 \%$ had a family history of stroke.

In the present study, more than half of cases $(78.5 \%)$ had not previous TIA. There was no statistically significant difference between the TIA as regard Duplex. In the study of El Tallawy et al. (2015) the prevalence of TIAs in this study was $0.15 / 1,000$ and the incidence was $0.05 / 1,000$. This is lower than the reported crude overall annual incidence of TIA in Northern Portugal per 1,000 populations $(0.67 ; 95 \%$ CI 0.45 to 1.04$)$. The lower prevalence rate of this study could be attributed to undervaluation of TIA cases. Thus, the lack of neurologists in Al Quseir, Egypt, can result in such cases being misdiagnosed as syncope attacks or any other medical conditions.

Surprisingly, $49.8 \%$ of cases arrived in the golden hours ( 4.5 hours or less ), $31.8 \%$ of cases came after 4.5 hours but within the first 24 hours and only $18.4 \%$ of cases came after 24 hours, this high percentage of early arrival could be explained by the restriction of our study on admitted patients and the higher probability of admission in patients viable to interventions rTPA and thrombectomy due to hospitals beds shortage and that is supported by another hospital based study in Egypt done by Al Serafy et al. (2016).

The current study showed that the most common site of infarct was parietal $29 \%$, basal ganglia $24.3 \%$ followed by cerebellar $8.4 \%$ and temporal $8.4 \%$, The first two locations were similar to previous study done by Bhowmik and 


\section{OSAMA EL-GHANNAM et al.,}

Abbas (2016) where parietal infarct counted $34.8 \%$ and basal ganglia $27.1 \%$. In this study the third most common site was internal capsule $26.2 \%$.

The current study showed that the linear regression model shows that males, hypertensive patients or smokers were higher in NIHS score, although the effect of each of age, gender, DM, HTN, smoking, and TIA history on NIHS score after adjusting for other variables was not significant. However, obesity had an independent significant effect on NIHS score adjusted for other variables where obese patients were more likely to have 1.83 more NIHS score than non-obese patients. The ordinal logistic regression shows that males, hypertensive patients or smokers were more likely to be in a higher category of severity (adjusted OR $=1.13$, $1.08,1.3$ respectively), although their effects were not significant after controlling other variables. However, the effect of obesity on stroke severity was significant where obese patients were 2.34 more likely to be in a higher category of stroke severity (adjusted OR $=2.34$ ) after adjusting for other predictors.

The cumulative risk of stroke recurrence within 5 years after a first episode range was between $15 \%$ and $40 \%$. The most relevant predictors of stroke recurrence identified in epidemiological trials include advancing age, hypertension, atrial fibrillation, diabetes mellitus, hyperlipidemia, and previous TIA. In the study of El Tallawy et al. (2015) previous stroke was reported in $12.9 \%$ of patients and was not correlated to age, sex, or risk factors except for diabetes. Moreover, stroke recurrence was significantly more among patients with ischemic stroke.
Robert and Zamzami (2014) found positive family history of stroke in $14 \%$ of stroke patients in Saudi Arabia. In the study of El Tallawy et al. (2015), a lower rate $(5 \%)$ was recorded, which can be attributed to lower level of consanguinity among Egyptians compared to Saudi Arabian population. Number of risk factors was significantly correlated with increasing age. While $20.3 \%$ of patients in the age group 40 years to $<60$ years had one risk factor, $47.1 \%$ of patients aged $60+$ had four and more risk factors for stroke.

\section{CONCLUSION}

In spite of the high prevalence of stroke risk factors among the study patients, the power was not enough to show any association with stroke severity except for smoking and obesity, where smokers and obese patients are more likely to have higher stroke severity.

\section{REFERENCES}

1. Abd-Allah F. and Moustafa RR, (2014): Burden of stroke in Egypt: current status and opportunities. Int J Stroke.; 9: 1105-1108.

2. Adria Arboix and Josefina Alio, (2010): cardio embolic stroke: clinical features, specific cardiac disorders and prognosis (2010) Curr Cardiol Rev. 2010 Aug; 6(3): $150-161$

3. Al-Baghli N., Aqeel J. AL-Ghamdi, Khalid A. Al-Turki, Ahmad G. El-Zubaier, Bader A. Al-Mostafa, Fadel A. Al-Baghli, and Mahmood M. Al-Ameer (2010): Awareness of cardiovascular disease in eastern Saudi Arabia. J Family Community Med. 2010 JanApr; 17(1): 15-21.

4. Al Serafy O. and Abdallah F. (2016): Epidemiology of stroke: A hospital based study in Alkasr Alainy 103-105. 
5. Alexander P. Coupland and AnkurThapar (2017): The definition of stroke Royal society of medicine $\mathrm{J}, 1: 1-25$.

6. Bhowmik N. and Abbas A. (2016): Ischemic strokes: Observations from a Hospital based stroke registry in Bangladesh (1-3):1-25.

7. Bum Joon Kim and Jong S. (2014): Ischemic stroke subtype classification: An Asian viewpoint J stroke. 2014 Jan; 16(1): 817. Published online 2014 Jan 31.

8. Chalachew Misganaw A., Sofia Kebede B. (2013): Assessment of stroke patients: occurrence of unusually high number of haemorrhagic stroke cases in Tikur Anbessa Specialized Hospital, Addis Ababa, Ethiopia. Clin Med Res. (2013); 2:94-100.

9. El Tallawy H., Farghaly W., Badry R. and Hamdy N. (2015): Epidemiology and clinical presentation of stroke in Upper Egypt (desert area). Neuropsychiatr Dis Treat. (2015); 11:2177-83.

10. Essa A., Helmy T. and El Batch S. (2011): Study of incidence, risk factors and outcome of acute cerebrovascular stroke patients admitted to Alexandria Main University Hospital. J Am Sci, (11):316-29.

11. Feigin VL., Krishnamurthi RV., Parmar P., Norrving B., Mensah GA. and Bennett DA. (2013): Update on the global burden of ischemic and hemorrhagic stroke in 19902013: the GBD 2013 Study. Neuroepidemiology. (2015); 45: 161-176.

12. Mahdi Habibi-koolaee, Leila Shahmoradi, Sharareh R. Niakan Kalhori, Hossein Ghannadan and Erfan Younesi (2018): Prevalence of Stroke Risk Factors and Their Distribution Based on Stroke Subtypes in Gorgan: A Retrospective Hospital-Based Study. Neurology research international (2018); 7: 380-386.
13. Khedr, E. M., Fawi, G., Abdela, M., Mohammed, T. A., Ahmed and M. A. ElFetoh (2014): Prevalence of ischemic and hemorrhagic strokes in Qena Governorate, Egypt: community-based study. Journal of Stroke and Cerebrovascular Diseases. 2014; 23(7), 1843-1848.

14. Lee M., Saver JL., Chang B., Chang KH., Hao Q. and Ovbiagele B. (2011): Presence of baseline prehypertension and risk of incident stroke: a meta-analysis. Neurology. 2011; Oct 4; 77(14):1330-7.

15. Rena S Shah and John W Cole, (2011): Smoking and stroke 2011 Expert Rev Cardiovasc Ther. 2010 Jul; 8(7): 917-932.

16. Robert AA. and Zamzami MM. (2014): Stroke in Saudi Arabia: a review of the recent literature. Pan Afr Med J. 2014; 17:14.

17. Roth GA., Johnson C., Abajobir A., AbdAllah F., Abera SF. and Abyu G. (2017): Global, regional, and national burden of cardiovascular diseases for 10 causes, 1990 to 2015. J Am Coll Cardiol. 2017; 70: 1-25.

18. Soliman R., Oraby M., Fathy M. and Essam A. (2018): Risk factors of acute ischemic stroke in patients presented to BeniSuef University Hospital: prevalence and relation to stroke severity at presentation. The Egyptian journal of neurology, psychiatry and neurosurgery. 2018; 54(1), 1-9.

19. Zhang Z., Yan J., Shi H. (2013): Hyperglycemia as a Risk Factor of Ischemic Stroke. J Drug Metab Toxicol. 2013 Jun 29; 4(4). 


\section{در اسة مستشفوية عن السكتة الدماغية الاحتنـائية فى مصر محمد صابر محمد حسن, طارق ابراهيم المنيسى, أحمدحسن الثيشينى}

\section{قسم طب المخ و الاعصاب، كلية الطب، جامعة الأزهر}

E-mail: afathyneuro@gmail.com

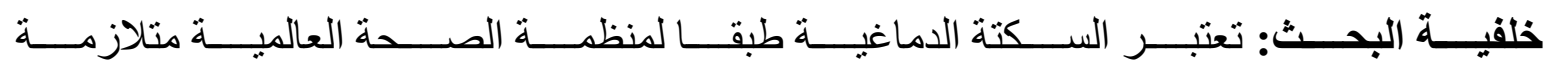

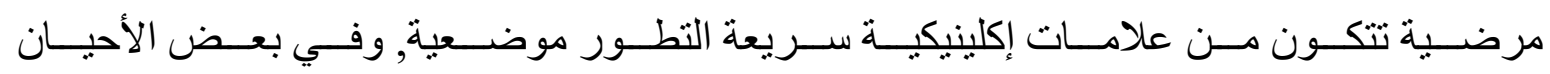

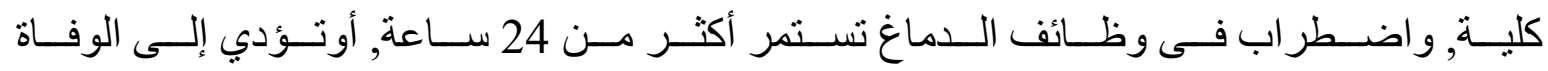
مع عدم وجود سبب واضح غير الأوعية الدموية.

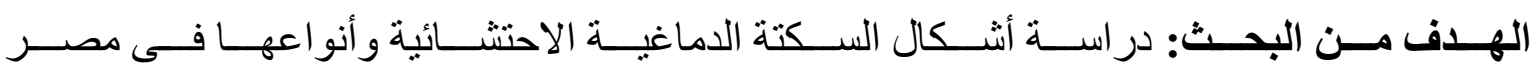
و أسبابها وطرق علاجها.

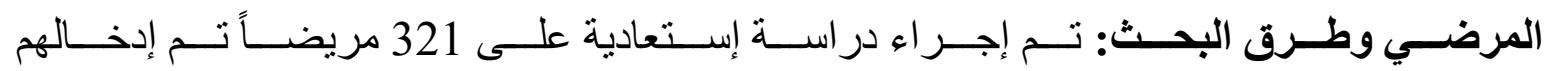

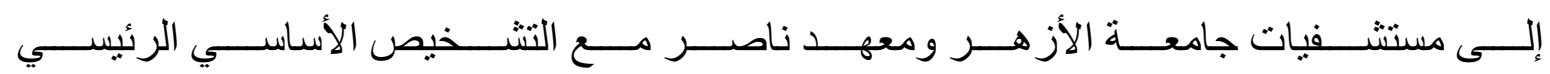
للسكتة الدماغية الحادة خلال الفترة من يناير 2017 حتى ديسمبر 2018.

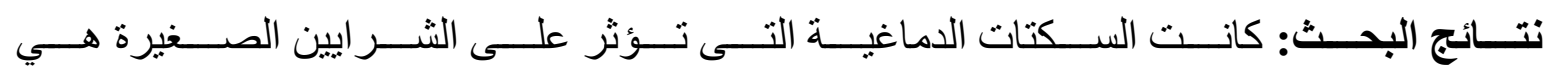

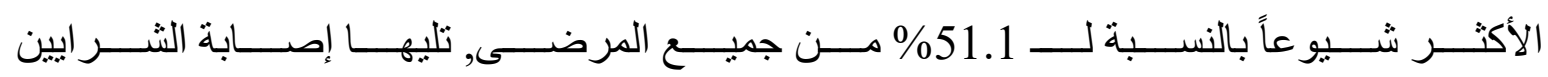

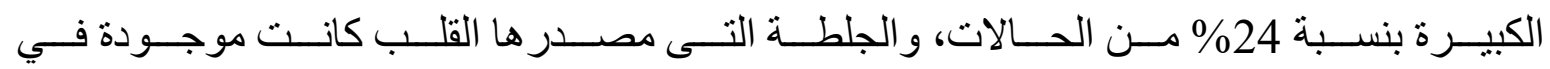

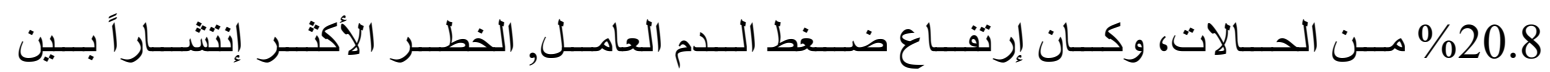

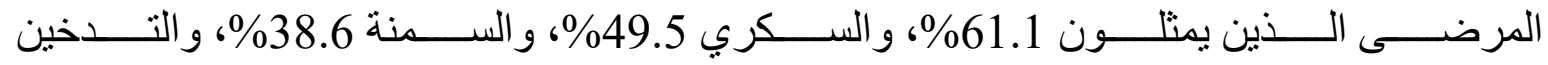

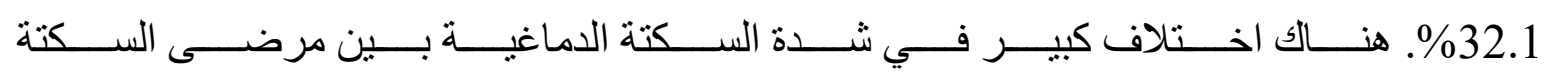

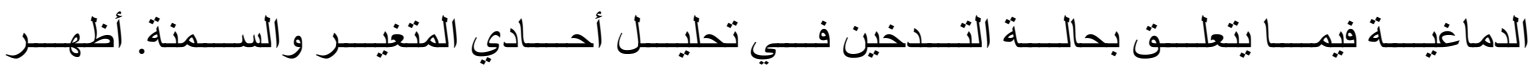

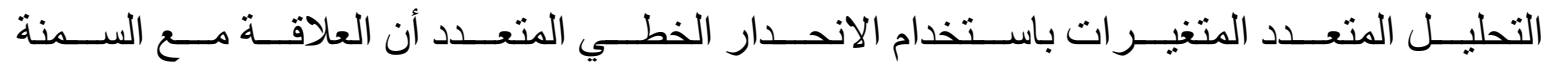
كانت ذات دلالية احصائية.

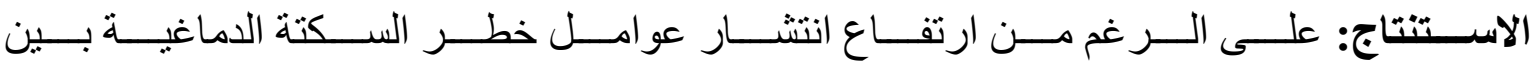

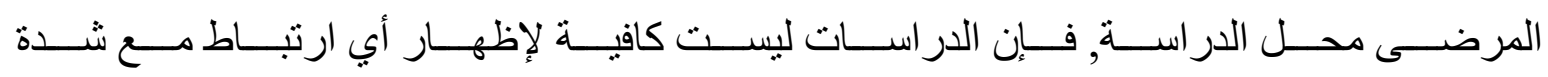

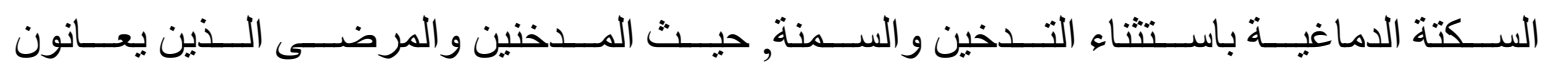
من السمنة المفرطة هم أكثر عرضة لجلطات اكثر شدة. 